\title{
Are You a Rabbit or a Turtle? A Comparative Analysis of the Pacing Profiles of the Turkish Origin and Non-Turkish Origin Elite Half-Marathon Athletes
}

\author{
Celil Kaçoğlu (Corresponding author) \\ Department of Coaching Education, Sport Sciences Faculty \\ Eskişehir Technical University, Eskişehir, Turkey \\ Tel: 90-506-401-7872Ｅ-mail: ckacoglu@eskisehir.edu.tr \\ İzzet Kırkaya \\ Department of Coaching Education, School of Physical Education and Sports \\ Yozgat Bozok University, Yozgat, Turkey \\ Tel: 90-555-491-2161Ｅ-mail: izzet.kirkaya@yobu.edu.tr
}

Received: May 11, 2020 Accepted: June 10, 2020 Published: June 20, 2020

doi:10.5296/jei.v6i1.17020ＵRL: https://doi.org/10.5296/jei.v6i1.17020

\begin{abstract}
The aim of this research was to designate and compare the pacing profiles of the Turkish and Non-Turkish female and male athletes completed and ranked in the first tenth $(n=79)$ in the determined half-marathon road races held in Turkey. The pacings of the athletes were divided into 5 separate segments $(0-5,5-10,10-15,15-21.1 \mathrm{~km})$ and calculated on the basis of their average transition speed (min:sec/km). The differences both between the pacing profiles of the Turkish and Non-Turkish athlete groups and between the successive segments within the groups were examined separately for women and men with the variance analysis for mixed patterns. According to the results, there was no statistical differences between the pacing profiles of both female and male Turkish and Non-Turkish athletes $(p>0.05)$. In addition, there was also no difference between the successive segments within the groups $(p>0.05)$. According to these results, it can be said that the pacing profiles of the Turkish and Non-Turkish elite athletes were similar and close to even pacing profile without a last sprint. Although it was not statistically significant, all the athletes had small decreases in their pacings in the first $15 \mathrm{~km}$ of the race. In the last $6.1 \mathrm{~km}$ segment, while small increases in the
\end{abstract}


pacings of the Non-Turkish female athletes were observed, the pacings of the Turkish women athletes were more even with small decreases. Considering the whole race, it was seen that the athletes showed pacing profiles close to positive and reverse J-shaped pacing profile.

Keywords: Nationality differences, Race strategies, Pacing strategies, Speed, Half-marathon

\section{Introduction}

Interest in long distance running, which many elite, amateur and recreational runners have completed, increases day by day. In recent years, the popularity of half-marathon organizations in cities has increased and these races have started to take place with the participation of large masses. For example, the number of registered athletes participating in the "Gothenburg" Half-Marathon organized since 1980 has been 1.4 million, while the "The Great North Run" Half-Marathon has been completed by 1 million people since 1981 (http://www.guinnessworldrecords.com/world-records/largest-half-marathon; https://www.got eborgsvarvet.se/en/goteborgsvarvet-half-marathon, Knechtle \& Nikolaidis, 2018). However, the fact that athletes with different performance levels participating in these organizations have different goals such as completing the race or winning the race reveals the diversity in the performances showed during the races. Each runner's distributing his/her energy according to his/her performance throughout the race would provide an optimal level of performance. Accordingly, in order for an athlete to effectively use his/her energy especially during aerobics endurance type performances, s/he must distribute the speed in accord with the whole activity, in other words, s/he must adjust her/his pacing (Foster et al., 2005; Abbiss \& Laursen, 2008; Roelands, de Koning, Foster, Hettinga, \& Meeusen, 2013).

The Aesopian tale where the turtle outruns the rabbit not by running fast but by maintaining its pacing until the end of the race draws attention to the importance of the concept of "pacing" (Foster, Schrager, Snyder, \& Thompson, 1994). One of the best examples emphasizing the importance of pacing is Dorando Pietri, who was exhausted, disoriented, even fell and then picked himself up a couple of times and crossed the finishing line with the help of the English attendants despite the fact that he was the first one to enter into the stadium in the marathon race in the 1908 London Olympic Games. The fact that the first place was given to Johnny Hayes, who finished the race in the second place, instead of Pietri who was disqualified due the help he received, shows that the concept of pacing is of vital importance especially in sports where durability becomes prominent (Foster et al., 1994). From that time, pacing strategy has become a critical factor in racing performances due to the fact that athletes' performances have increased steadily and performance differences between athletes have started to decrease (Hettinga, De, Meijer, Teunissen, \& Foster, 2007; Renfree \& Gibson, 2013). Because, in order for a well-trained athlete to be able to reach the upper limits of his/her performance, s/he should distribute the workload or energy consumption during the race to the whole race in the most efficient way with these kinds of strategies (Foster, De Koning, Hettinga, Lampen, La Clair, Dodge, Bobbert, \& Porcari, 2003; Hettinga et al., 2007; Abbiss \& Laursen, 2008).

During long distance running races such as half-marathons, the best pacing strategy and sustaining physiological energy stores with the control of this strategy throughout the race are 
very effective in the athlete's ability to complete the race in the best time (Carmo, Barretti, Ugrinowitsch, \& Tricoli, 2012). Therefore, an athlete should avoid wasting his/her energy, however, when he reaches the finish line, he must have used all the energy stores. But when there is a long distance to the finish, his/her consumption of the existing energy sources, such as muscle glycogen and blood glucose, would lead to a drastic decrease in his/her racing (Foster et al., 2003). Conversely, an athlete's crossing the finish line with full energy stores and strength is the result is an error in the pacing strategy $\mathrm{s} /$ he follows during the race (Foster et al., 2005). In other words, with a fast finishing strategy, a runner being too cautious with a low pacing throughout the race might finish the race with poor performance despite accelerating at the end of the race (Smyth, 2018). If an athlete can determine his/her own exercise workload during the races of running (Wu et al., 2015), swimming (De Koning et al., 2001), open sea swimming (Baldassarre, Bonifazi, \& Piacentini, 2018), paddle (Garland, 2005), speed skating (Muehlbauer, Panzer, \& Schindler, 2010), cycling (Hettinga, De Koning, Broersen, Van Geffen, \& Foster, 2006), ultra-marathon (Knechtle, Rosemann, Zingg, Stiefel, \& Rüst, 2015), ski running (Nikolaidis, Ćuk, \& Knechtle, 2019) or olympic/ironman/ deca-ultra-triathlon (Herbst et al., 2001; Wu et al., 2015), s/he can adjust his/her pace to prevent changes that may limit or decrease his/her performance in physiological systems (Tucker \& Noakes, 2009). In this respect, pacing strategy can be defined as the most efficient use of energy resources by the strategy or tactics adopted by the athlete from the beginning to complete the race in the shortest time possible (Tucker \& Noakes, 2009; Lima-Silva et al., 2010; Roelands et al., 2013). However, it should be noted that the concept of pacing refers to performance times or speeds rather than the mechanical work or power output generated. Nevertheless, pacing adjustment is largely determined by the ability to resist fatigue, which is very important to a large extent in mechanical output (Abbiss \& Laursen, 2008).

Coaches and athletes use different pacing strategies such as positive, negative, even, all-out, variable and parabolic (U-shaped, J-shaped, reverse J-shaped) depending on the duration, distance and speed of the race (Figure 1).

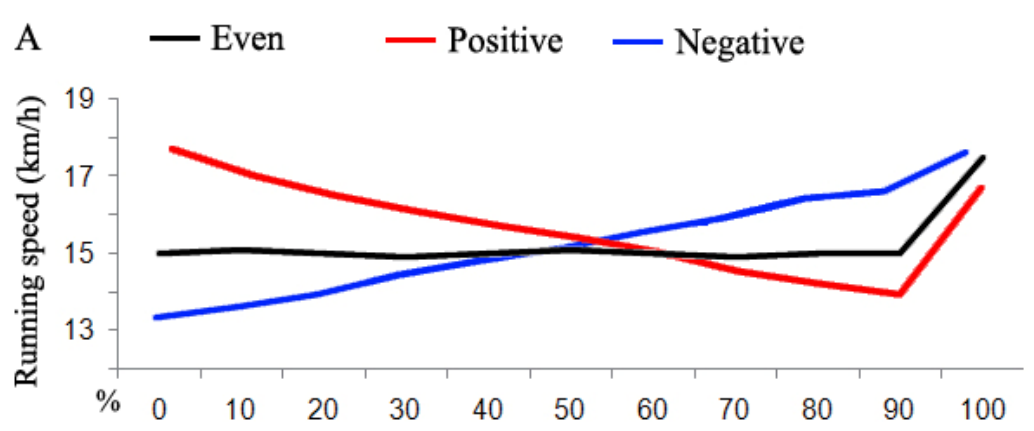

Figure 1a. Graphical representation of different pacing strategies used in long distance races (adapted from Carmo et al., 2012) 


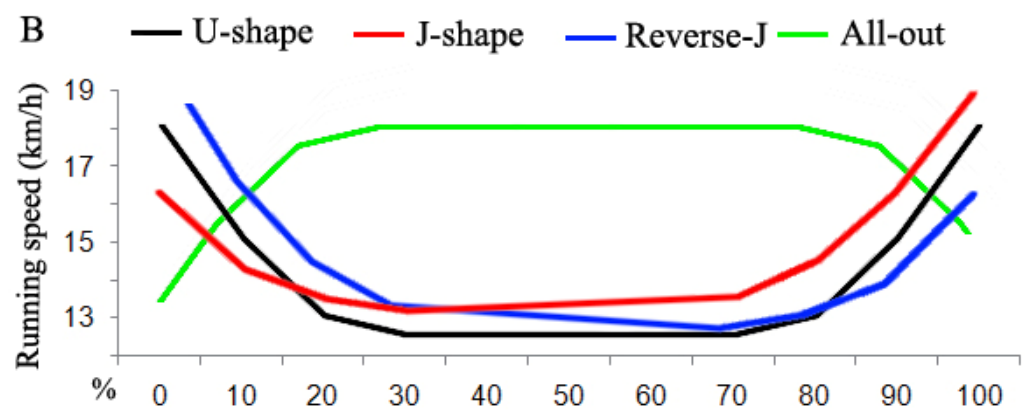

Figure 1b. Graphical representation of different pacing strategies used in long distance races (adapted from Carmo et al., 2012)

To explain these strategies briefly, in positive strategy, the speed of the athlete gradually decreases throughout the race. In negative strategy, the speed increases gradually during the race. In balanced strategy, the speed is constant to a large extent throughout the race. In all-out strategy, the speed accelerates at the beginning of the race, remains stable and then declines gradually. In variable strategy, the speed fluctuates in a non-systematic way. Parabolic strategy has three sub-strategies which are U-shaped, J-shaped and reverse J-shaped. In U-shaped parabolic strategy, the speed decreases in the first part of the race and increases in the second half. In U-shaped and J-shaped strategies, a speed increase defined as an attack or final sprint is observed in the last $10 \%$ of the race. What distinguishes J-shaped strategy from the U-shape strategy is that the end-of-race speed is higher than the starting speed. In reverse J-shaped strategy, the starting speed is higher than the speed at the end of the race (Abbiss \& Laursen, 2008; Roelands et al., 2013).

When the studies on short and medium distances are examined, for example, those who perform better in a 4-minute running race against time were observed to have a more aggressive pacing strategy in the first 2 minutes of run (Watkins, Platt, Andersson, \& McGawley, 2017). Similarly, a pacing which has a feature of a 5-minute cycling performance against time with a fast starting strategy is more compared to even strategies with slow starting (Aisbett, Le Rossignol, McConell, Abbiss, \& Snow, 2009). In almost all of the middle distance ( 400 and $800 \mathrm{~m}$ ) running races, the first half of the race is faster than the second half (Reardon, 2013). As a result of the $10 \mathrm{~km}$ track running test conducted against the clock in the form of a racing simulation, the runners with average performances $(16.9 \mathrm{~km} / \mathrm{h})$ showed a U-shaped parabolic pacing profile with a fast start, while runners with lower performances $(14.9 \mathrm{~km} / \mathrm{h})$ were observed to adopt an even strategy at a more constant speed throughout the whole race (Damasceno et al., 2011). Although in middle and long distance races, it is stated that even pacing strategy is the most ideal pacing strategy (Abbiss \& Laursen, 2008), it is also known that there are elite long distance runners using different pacing strategies (Angus, 2014).

The similarity of blood lactate and $\mathrm{Ph}$ values in slow and even strategies with a fast start reveals that pacing strategies do not affect some physiological parameters (Aisbett et al., 
2009). Yet some relatively low-performance runners can push themselves to run faster than their ideal pacing to keep up with the runners running in the front group. But this situation might lead to earlier emergence of fatigue and decrease pacing gradually (Thiel, Foster, Banzer, \& De Koning, 2012). In addition, internal factors such as current energy stores, hydration levels, neuromuscular fatigue, cardiorespiratory performance, external factors such as condition of race track, convenience of environmental conditions, factors such as nationality, tactical changes and also decision-making processes of runners such as psychological readiness, mental adequacy, effort perceptions, psycho-biological conditions, behavioral characteristics have important roles on a runner's ability of sustaining the determined racing strategy (Pageaux, 2014; Hanley, 2015; Pageaux \& Lepers, 2016; Van Biesen, Hettinga, McCulloch, \& Vanlandewijck, 2016; Aschmann, Knechtle, Onywera, \& Nikolaidis, 2018; Filipas, Ballati, Bonato, La Torre, \& Piacentini, 2018; Robinson, Cloak, Lahart, \& Lane, 2018). Besides, while pacing profiles may be a strategy for elite athletes, they may also vary due to the interaction of the front group in the race or the structure of the race track. It should be noted that human and environmental interactions, such as weather conditions and hypoxic conditions, may also affect the pacing (Ely, Martin, Cheuvront, \& Montain, 2008; Tucker \& Noakes, 2009; Roelands et al., 2013; Skorski \& Abbiss, 2017; Konings \& Hettinga, 2018). In addition to environmental factors such as oxygen level and humidity (Tucker \& Noakes, 2009; Roelands et al., 2013), there are also many other factors such as kinetic, biomechanical and also physical or mental fatigue before the race, which affect the performance of an athlete in big and challenging races like marathons and half-marathons (Skorski \& Abbiss, 2017). Therefore, it is stated that it is more appropriate to use pacing profile instead of pacing strategy in the studies about pacing profiles (Santos-Lozano, Collado, Foster, Lucia, \& Garatachea, 2014).

The half-marathon does not have a legendary past and a hero like Pheidippides, like the marathon. Pheidippides had no friend to whom he stopped halfway down the road and said "Hey, I completed the half way. I invented a new activity." (Higdon, 2016). While the emergence of the concept of half-marathon in the world dates back to 1950-1960's, the International Association of Athletics Federation (IAAF) started to organize "The Half-Marathon World Championship" in 1992 (Hanley, 2015; Higdon, 2016).

In the last 50-60 years, the half-marathon World record has increased for about 9 minutes (from 1:07:01 to 58:18) for men and about 19 minutes for women (https://arrs.run/ RecProg/RP_wwR.htm). The current record holder is Abraham Kiptum with a 58:18 clocking in men (2018) and Joyciline Jepkosgei with a 1:04:51 clocking in women (2017) (https://www.iaaf.org/records/by-discipline/road-running/half-marathon/outdoor/men; https:// www.iaaf.org/records/by-discipline/road-running/half-marathon/outdoor/women). As for the record in Turkey, Kaan Kigen Özbilen set the record with a 59:48 clocking in men in 2019, Elvan Abeylegesse set the record with a 1:07:07 clocking in women in 2010 (http://www.taf.org.tr/turkiye-acik-saha-rekorlari). For the last 30 years, it is observed that half-marathon road races have changed into events with more participation compared to marathon for long distance running lovers both in the world and in our country due to its being in a more accessible distance compared to marathon race (Hanley, 2015; Knechtle et al., 
2014; Higdon, 2016). The number of people completing half-marathon is 2.6 and 3.7 times higher than those completing marathon in European countries and in the USA respectively (Knechtle et al., 2016).

In international studies, it is seen that there are studies on the pacing profiles of both elite athletes and more amateur and recreational athletes (Hanley, 2015). Although pacing has an important role in optimizing individual performances of runners (Santos-Lozano et al., 2014; Maffetone, Malcata, Rivera, \& Laursen, 2017; Kais, Pind, Pehme, Kaasik, \& Mooses, 2019), no research results on the race pacing profiles of athletes in relation to long distance races such as the half-marathon at the national level could be found. The analysis of specific race pacing profiles of Turkish and Non-Turkish elite athletes will be able to provide important information on developing strategy for athletes, and training program for coaches. Starting from this, the aim of this study is to determine and compare the basic pacing profiles of Turkish and Non-Turkish elite runners who completed the National Half-Marathon races matching some determined criteria.

\section{Method}

A retrospective observational and quantitative-based cross-sectional study design was used in this study. In this study, it is aimed to reveal information about pace profiles of elite runners. It is thought to be useful in determining both accessible goals according to elite national athletes' performances and race strategies.

The aim of this observational study, which is conducted to define race pacing profiles, is to determine and compare the pacing profiles of male and female elite athletes who completed the races in the first 10 places. These races were chosen among the national half-marathons with IAAF certification organized in 2018 (https://media.aws.iaaf.org/competitioninfo/ a1cbfaa3-8121-4fd3-8c87-ffa434a0b1d5.pdf). The inclusion criteria were determined the race split times at 0-5 km, 5-10 km, 10-15 km and 15-21.1 km. According to this, 2 half-marathon races constitute the sample of the study. The national half-marathons which can be reached by open access from the official websites of the determined race organizations were included in the study. During the research Helsinki Declaration was followed and this study was approved by Eskişehir Technical University, Scientific Research and Publication Ethics Committee (Date: 10 April 2020; Document no: 87914409-050.99).

\subsection{Data Collection}

For the analysis of the data, the race running times of the Turkish and Non-Turkish male and female athletes, who completed two national half-marathon races matching the inclusion criteria in the top ten places, were used. The half-marathon times were based on the athletes' transition times between the start and finish lines of the race. Transition times for the 4 parts of the race were converted to the average running speeds due to the speed being more symmetrical, normally distributed and linearly associated with other data (min:sec/ $\mathrm{km}$ ) (Nevill \& Whyte, 2005; Renfree \& Gibson, 2013). Race pacings were analyzed by dividing the race results in 4 parts which were $5 \mathrm{~km}$ long parts $(0-5 \mathrm{~km}, 5-10 \mathrm{~km}, 10-15 \mathrm{~km})$ and in addition, the last $6.1 \mathrm{~km}$ long part $(15-21.1 \mathrm{~km})$ of the race. 20 Turkish, 20 Non-Turkish male 
and 20 Turkish, 19 Non-Turkish female athletes who completed the Half-Marathon in the first ten places, were included in this study $(n=79)$. In addition, $84 \%$ of Non-Turkish female and male athletes were from Kenya and Ethiopia.

\subsection{Statistical Analysis}

All data were given as average and standard deviation, it was seen that the data were normally distributed in Q-Q Plot Graphs and it was determined with Box graphs that there was no runner who had extreme values. Variance analysis was used for mixed patterns in order to determine both changes in pacing between the parts within the groups and difference between the groups for the same parts. Mauchly sphericity test was used to determine the equality of variance and covariance, Greenhouse-Geisser correction was used when this assumption was not provided, the effect size was determined with partial eta squared and the statistical significance level was determined as $\mathrm{p}<0.05$. In the case of a significant difference in the result of the ANOVA test, Tukey or Games-Howell post-hoc (Suitable for unequal variances) tests were used to determine between which of two values the difference is. All statistical calculations were performed by using SPSS v.20 software.

\section{Results}

In Table 1, the pacing averages designated separately for men and women as the average $\mathrm{km}$ transition times (in each segment) of the individuals in Turkish origin and Non-Turkish origin athlete groups.

Table 1. Descriptive statistics on the average segment pacing of the performance groups (min:sec \pm sec)

\begin{tabular}{|l|l|l|l|l|l|l|}
\hline & & $\mathbf{N}$ & $\mathbf{5} \mathbf{~ k m}$ & $\mathbf{1 0} \mathbf{~ k m}$ & $\mathbf{1 5} \mathbf{~ k m}$ & $\mathbf{2 1 . 1} \mathbf{~ k m}$ \\
\hline \multirow{3}{*}{ Female } & Non-Turkish group & 19 & $03: 19 \pm 16$ & $03: 21 \pm 18$ & $03: 29 \pm 20$ & $03: 30 \pm 15$ \\
\cline { 2 - 7 } & Turkish group & 20 & $03: 50 \pm 14$ & $03: 51 \pm 11$ & $03: 59 \pm 13$ & $03: 56 \pm 16$ \\
\hline \multirow{3}{*}{ Male } & Non-Turkish group & 20 & $02: 58 \pm 07$ & $02: 57 \pm 08$ & $03: 00 \pm 10$ & $02: 59 \pm 08$ \\
\cline { 2 - 7 } & Turkish group & 20 & $03: 16 \pm 13$ & $03: 16 \pm 10$ & $03: 21 \pm 08$ & $03: 21 \pm 14$ \\
\hline
\end{tabular}

Note. Mean \pm Standard deviation.

As a result of the variance analysis for mixed patterns $(2 \times 4)$, it was seen that, for both female $(F=0.768, p>0.05$, effect size $=0.020)$ and male $(F=0.495, p>0.05$, effect size $=$ 0.013 ) athletes, there was no statistically significant interaction (within-subject effect) between the pacing profiles of the Turkish and Non-Turkish groups. According to this, it can be said that the pacing profiles of both female (Figure 2a) and male (Figure 2b) Turkish and Non-Turkish elite athletes are similar. According to the results of the simple main effect, separately for female and male athletes, it was seen that there was no statistically significant difference in the average pacing of Turkish and Non-Turkish elite groups between the segments (between subject effect) $(\mathrm{p}>0.05)$. According to Tukey Poc-host multiple 
comparison results, it was seen that there was no statistically significant difference between all the binaries $(\mathrm{p}>0.05)$.

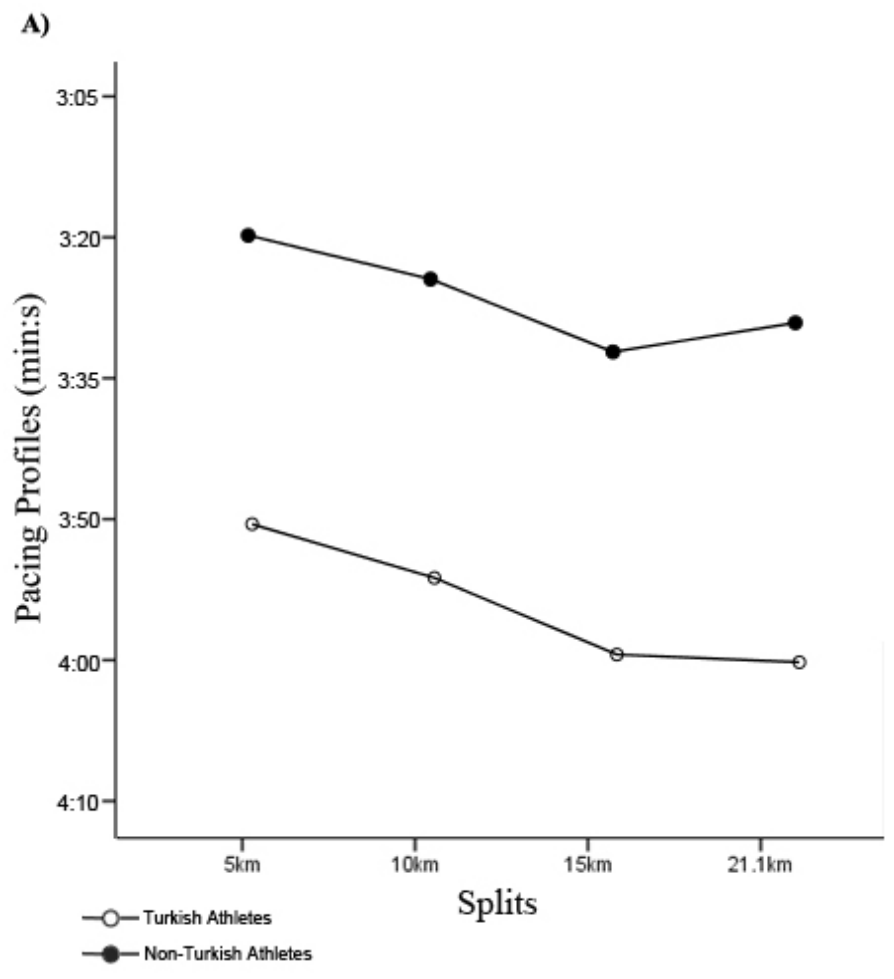

B)

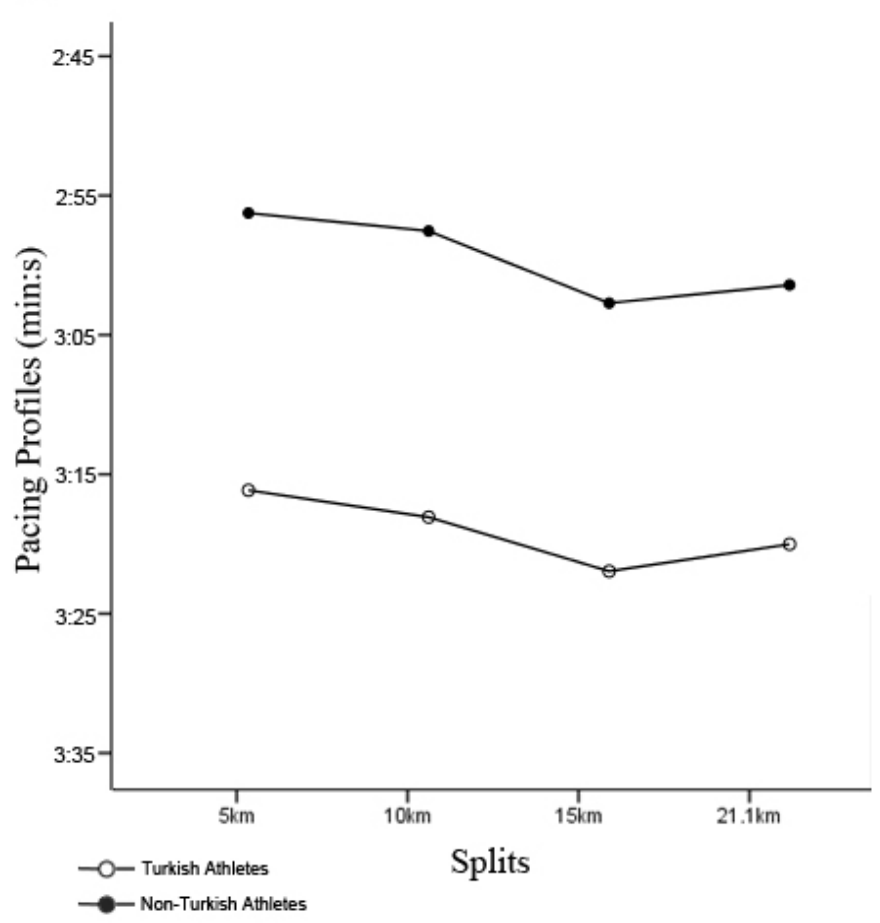

Figure 2. Differences between the successive inter-segments average pacing times in the Turkish and Non-Turkish elite female (a) and male (b) athlete groups $\mathrm{p}<0.05(\S), \mathrm{p} \leq 0.001(*)$ 
As it can be seen in Figure 2, while the pacing profiles of female Turkish athletes are slightly lower, their pacing profiles show similarity with the pacing profiles of Non-Turkish elite athletes $(p>0.05)$. It is seen that there is a small decrease in the pacing profiles of Turkish and Non-Turkish women athletes in the $0-10 \mathrm{~km}$ part of the half-marathon. The pacings of Turkish and Non-Turkish athletes show a downward trend in both women and men between $10-15 \mathrm{~km}$. In the last $6.1 \mathrm{~km}$ part, there is a statistically insignificant slight increase in the pacings of the Non-Turkish women athletes and there is a small decrease in the pacings of the Turkish women, while male athletes show a more even pacing with small pacing increases $(p>0.05)$. Although the pacings of the Turkish male athletes are lower compared to Non-Turkish runners, both Turkish and Non-Turkish athletes show an even pacing profile throughout the race.

\section{Discussion}

The aim of this study was to define the pacing profiles of the Turkish and Non-Turkish elite athletes during the race and to compare the pacing profiles between the Turkish and Non-Turkish athletes on the basis of gender. According to the results, it was observed that the pacings of the Turkish and Non-Turkish athletes were similar. It would not be wrong to say that the female Turkish athletes showed a pacing profile close to positive, the Non-Turkish elite women were more close to reverse J-shaped pacing profile and that the Turkish and Non-Turkish male athletes showed a more even pacing profile. Besides, it was observed that there was no pacing increase defined as last sprint in the last part of the half-marathon race. Although there was no last sprint at the end of the race, there was no deceleration in the pacings of the male elite athletes while there was a small increase in the pacings of the Non-Turkish elite women and contrary to this, a small decrease in the pacings of the Turkish women.

In Hanley (2015)'s research about the pacing profiles in the IAAF Half-Marathon Championships, it was stated that the male and female athletes showed pacing profiles close to positive pacing profile with last sprint. It is seen that there were similarities, except for the last sprint, in the pacing profiles of the Turkish and Non-Turkish elite athletes in the half-marathon road races organized at the national level. Despite the fact that elite athletes were analyzed in both studies, the fact that in contrast to Hanley (2015) research results, there was no last sprint in this study suggests that it may be related to the number of samples. Besides, if the last sprint at the end of the race is considered as a race pacing strategy, since the absence of compelling competitors for medal competition may reduce the need for the last sprint, it can be interpreted as the reason for the last sprint in the national half-marathons being relatively less seen (Tomazini et al., 2015).

It is stated that the most effective pacing strategy in long distance endurance races is the strategy characterized by minimum speed changes (Diaz, Fernandez-Ozcorta, \& Santos-Concejero, 2018). Also researches show that Ethiopian and Kenya athletes show a more even pacing profile in long distance running races than athletes of other nations (Aschmann et al., 2018). When evaluated from this point, the fact that according to the results of this research, there is no statistically significant pacing difference between successive 
inter-segments supports this information. Accordingly, it is important for coaches to evaluate pacing strategies of their athletes and competing athletes according to their nationality. Nikolaidis, Villiger, \& Knechtle, (2018) revealed that half-marathon pacing profiles showed positive pacing strategy without last sprint. The pacing profiles of the Turkish and Non-Turkish athletes can be said to be similar to these results.

While the pacing profiles of the runners with marathon world record showed positive structure in the past years, in current records this pacing profile has started to change towards negative profile in which the last 5 kilometers of the race is the fastest (Diaz et al., 2018). In this respect, it can be said that it differs from this research's result in terms of pacing profiles without a statistically significant last sprint.

In this study, the inclusion of 2 half-marathons except for the uncontrolled internal and external factors was considered as a limitation. Because researches in larger sample groups would provide useful results in reaching more general results. In addition, pacing profile evaluation was based on the data obtained from 4 segments of the race distance. Evaluations with more simultaneous pacing graphics or with more segments will be able to reveal more detailed pacing changes. Therefore, it is thought that the results of this study will provide information for future studies. Besides, it is hoped that in the future, it will lead the national researches to be conducted in sports where endurance is prominent such as long distance running as well as road bike, open-sea swimming, triathlon, ultra-marathon and ski-run.

The result is that the pacings of the female and male Turkish and Non-Turkish elite athletes who completed the half-marathon race are similar. Another result is that the half-marathon pacing profiles do not contain a significant last sprint in both male and female Turkish and Non-Turkish athletes and showed features of a gradually decreasing positive pacing strategy throughout the race. While planning training programs, coaches' and athletes' paying attention to this information that they can gain with these results about the direction of the half-marathon pacing profiles of the Turkish and Non-Turkish elite athletes would contribute positively to athletes' performances. In addition, these results about the half-marathon pacing profiles of the Turkish and Non-Turkish elite athletes will be a source for athletes to use in their effort to develop racing strategies in race and try runs. Besides, it is thought that it will contribute to the literature as a source for athletes to get important information about how to distribute their energies evenly to the whole race during half-marathon races and about consuming the remaining energy stores entirely with last sprint as much as it is needed at the right time in the last segment of the race. It is hoped that, with various researches to be made in the future, the relation between pacing strategies and performance will be revealed and provide insights for runners or it is possible to study about the pacing strategies between gender or age differences in specific city half-marathons.

\section{References}

Abbiss, C. R., \& Laursen, P. B. (2008). Describing and understanding pacing strategies during athletic competition. Sports Medicine, 38(3), 239-252. https://doi.org/10.2165/0000 7256-200838030-00004 
Aisbett, B., Le Rossignol, P., McConell, G. K., Abbiss, C. R., \& Snow, R. (2009). Effects of starting strategy on 5-min cycling time-trial performance. Journal of Sports Sciences, 27(11), 1201-1209. https://doi.org/10.1080/02640410903114372

Angus, S. D. (2014). Did recent world record marathon runners employ optimal pacing strategies? Journal of Sports Sciences, 32(1), 31-45. https://doi.org/10.1080/02640414.2013. 803592

Aschmann, A., Knechtle, B., Onywera, V., \& Nikolaidis, P. T. (2018). Pacing strategies in the New York City Marathon-Does nationality of finishers matter? Asian Journal of Sports Medicine, 9(2), 1a-1a. https://doi.org/10.5812/asjsm.57596

Baldassarre, R., Bonifazi, M., \& Piacentini, M. F. (2018). Pacing profile in the main international open-water swimming competitions. European Journal of Sport Science, 1-10. https://doi.org/10.1080/17461391.2018.1527946

Carmo, E. C. D., Barretti, D. L. M., Ugrinowitsch, C., \& Tricoli, V. A. A. (2012). Estratégia de corrida em média e longa distância: Como ocorrem os ajustes de velocidade ao longo da prova? Revista Brasileira de Educação Física e Esporte, 26(2), 351-363. https://doi.org/ 10.1590/S1807-55092012000200016

Damasceno, M. V., Bertuzzi, R., Pires, F. O., Oliveira, C. C., Barros, R. V., Gagliardi, J. F. L., ... Lima-Silva, A. E. (2011). Relationship between oxygen uptake kinetics and the running strategy on a $10 \mathrm{~km}$ race. Revista Brasileira de Medicina do Esporte, 17(5), 354-357. https://doi.org/10.1590/S1517-86922011000500012

De Koning, J. J., Foster, C., Lucia, A., Bobbert, M. F., Hettinga, F. J., \& Porcari, J. P. (2001). Using modeling to understand how athletes in different disciplines solve the same problem: Swimming versus running versus speed skating. International Journal of Sports Physiology and Performance, 6(2), 276-280. https://doi.org/10.1123/ijspp.6.2.276

Diaz, J. J., Fernandez-Ozcorta, E. J., \& Santos-Concejero, J. (2018). The influence of pacing strategy on marathon world records. European Journal of Sport Science, 1-6. https://doi.org/ 10.1080/17461391.2018.1450899

Ely, M. R., Martin, D. E., Cheuvront, S. N., \& Montain, S. J. (2008). Effect of ambient temperature on marathon pacing is dependent on runner ability. Medicine \& Science in Sports \& Exercise, 40(9), 1675-1680. https://doi.org/10.1249/MSS.0b013e3181788da9

Filipas, L., Ballati, E. N., Bonato, M., La Torre, A., \& Piacentini, M. F. (2018). Elite male and female 800-m runners display different pacing strategies during seasons best performances. International Journal of Sports Physiology and Performance, 1-20. https://doi.org/10.1123/ ijspp.2018-0137

Foster, C., De Koning, J. J., Hettinga, F., Lampen, J., La Clair, K. L., Dodge, C., .. Porcari, J. P. (2003). Pattern of energy expenditure during simulated competition. Medicine \& Science in Sports \& Exercise, 35(5), 826-831. 


\section{MInstitute Macrothink $_{\text {Int }}$}

Foster, C., de Koning, J., Bakkum, A., Kloppenburg, S., Porcari, J. P., Splinter, A., ... van Tunen, J. (2005). What is pacing? In G. T. Kevin (Ed.), Pacing: Individual strategies for optimal performance (pp. 3-5). Champaign, IL: Human Kinetics.

Foster, C., Schrager, M., Snyder, A. C., \& Thompson, N. N. (1994). Pacing strategy and athletic performance. Sports Medicine, 17(2), 77-85. https://doi.org/10.2165/00007256-19941 7020-00001

Garland, S. W. (2005). An analysis of the pacing strategy adopted by elite competitors in 2000m rowing. British Journal of Sports Medicine, 39(1), 39-42. https://doi.org/10.1136/ bjsm.2003.010801

Hanley, B. (2015). Pacing profiles and pack running at the IAAF World Half Marathon Championships. Journal of Sports Sciences, 33(11), 1189-1195. https://doi.org/10.1080/ 02640414.2014 .988742

Herbst, L., Knechtle, B., Lopez, C.L., Andonie, J. L., Fraire, O. S., Kohler, G., ... Rosemann, T. (2001). Pacing strategy and change in body composition during a Deca Iron triathlon. Chin J Physiol, 54(4), 255-263. https://doi.org/10.4077/CJP.2011.AMM115

Hettinga, F. J., De Koning, J. J., Broersen, F. T., Van Geffen, P., \& Foster, C. (2006). Pacing strategy and the occurrence of fatigue in 4000-m cycling time trials. Medicine \& Science in Sports \& Exercise, 38(8), 1484-1491. https://doi.org/10.1249/01.mss.0000228956.75344. 91

Hettinga, F. J., De, J. K., Meijer, E., Teunissen, L., \& Foster, C. (2007). Effect of pacing strategy on energy expenditure during a 1500-m cycling time trial. Medicine and Science in Sports and Exercise, 39(12), 2212-2218. https://doi.org/10.1249/mss.0b013e318156e8d4

Higdon H. (2016). Hal Higdon's Half Marathon Training (p. 14). Champaign, IL: Human Kinetics.

Kais, Ü., Pind, R., Pehme, A., Kaasik, P., \& Mooses, M. (2019). Pacing strategy of the finishers of the World Marathon Majors Series. Kinesiology: International Journal of Fundamental and Applied Kinesiology, 51(1), 5-6. https://doi.org/10.26582/k.51.1.5

Knechtle, B., \& Nikolaidis, P. T. (2018). Sex-and age-related differences in half-marathon performance and competitiveness in the World's largest half-marathon-The Göteborgs Varvet. Research in Sports Medicine, 26(1), 75-85. https://doi.org/10.1080/15438627.2017. 1393749

Knechtle, B., Barandun, U., Knechtle, P., Zingg, M. A., Rosemann, T., \& Rüst, C. A. (2014). Prediction of half-marathon race time in recreational female and male runners. SpringerPlus, 3(1), 248. https://doi.org/10.1186/2193-1801-3-248

Knechtle, B., Nikolaidis, P. T., Onywera, V. O., Zingg, M. A., Rosemann, T., \& Rüst, C. A. (2016). Male and female Ethiopian and Kenyan runners are the fastest and the youngest in both half and full marathon. SpringerPlus, 5(1), 223. https://doi.org/10.1186/s40064-016$1915-0$ 
Knechtle, B., Rosemann, T., Zingg, M. A., Stiefel, M., \& Rüst, C. A. (2015). Pacing strategy in male elite and age group $100 \mathrm{~km}$ ultra-marathoners. Open Access Journal of Sports Medicine, 6, 71. https://doi.org/10.2147/OAJSM.S79568

Konings, M. J., \& Hettinga, F. J. (2018). Pacing decision making in sport and the effects of interpersonal competition: A critical review. Sports Medicine, 1-15. https://doi.org/10.1007/ s40279-018-0937-x

Lima-Silva, A. E., Bertuzzi, R. C., Pires, F. O., Barros, R. V., Gagliardi, J. F., Hammond, J., ... Bishop, D. J. (2010). Effect of performance level on pacing strategy during a 10-km running race. European Journal of Applied Physiology, 108(5), 1045-1053. https://doi.org/ 10.1007/s00421-009-1300-6

Maffetone, P. B., Malcata, R., Rivera, I., \& Laursen, P. B. (2017). The Boston Marathon versus the World Marathon Majors. PloS One, 12(9), e0184024. https://doi.org/10.1371/ journal.pone.0184024

Muehlbauer, T., Panzer, S., \& Schindler, C. (2010). Pacing pattern and speed skating performance in competitive long-distance events. J Strength Cond Res., 24(1), 114-119. https://doi.org/10.1519/JSC.0b013e3181c6a04a

Nevill, A. M., \& Whyte, G. (2005). Are there limits to running world records?. Medicine \& Science in Sports \& Exercise, 37(10), 1785-1788. https://doi.org/10.1249/01.mss.0000181676. 62054.79

Nikolaidis, P. T., Ćuk, I., \& Knechtle, B. (2019). Pacing of women and men in half-marathon and marathon races. Medicina, 55(1), 14. https://doi.org/10.3390/medicina55010014

Nikolaidis, P. T., Villiger, E., \& Knechtle, B. (2018). The effect of sex and performance level on pacing in cross-country skiers: Vasaloppet 2004-2017. Journal of Sport and Health Science, 7, 453-458. https://doi.org/10.1016/j.jshs.2018.03.005

Pageaux, B. (2014). The psychobiological model of endurance performance: An effort-based decision-making theory to explain self-paced endurance performance. Sports Medicine, 44(9), 1319. https://doi.org/10.1007/s40279-014-0198-2

Pageaux, B., \& Lepers, R. (2016). Fatigue induced by physical and mental exertion increases perception of effort and impairs subsequent endurance performance. Front Physiol, 7, 587. https://doi.org/10.3389/fphys.2016.00587

Reardon, J. (2013). Optimal pacing for running 400-and 800-m track races. American Journal of Physics, 81(6), 428-435. https://doi.org/10.1119/1.4803068

Renfree, A., \& Gibson, A. S. C. (2013). Influence of different performance levels on pacing strategy during the Women's World Championship marathon race. International Journal of Sports Physiology and Performance, 8(3), 279-285. https://doi.org/10.1123/ijspp.8.3.279 


\section{MInstitute Macrothink $_{\text {Int }}$}

Robinson, D. T., Cloak, R., Lahart, I. M., \& Lane, A. M. (2018). Do I focus on the process of cycling or try to put my mind elsewhere? A comparison of concentration strategies for use in pacing by novice riders. In M. Samuele, \& S. Mustafa (Eds.), Sport and the brain: The science of preparing, enduring and winning (p. 128, Part C, Chapter 8, Vol. 240). Academic Press: Elsevier.

Roelands, B., de Koning, J., Foster, C., Hettinga, F., \& Meeusen, R. (2013). Neurophysiological determinants of theoretical concepts and mechanisms involved in pacing. Sports Medicine, 43(5), 301-311. https://doi.org/10.1007/s40279-013-0030-4

Santos-Lozano, A., Collado, P. S., Foster, C., Lucia, A., \& Garatachea, N. (2014). Influence of sex and level on marathon pacing strategy. Insights from the New York City race. International Journal of Sports Medicine, 35(11), 933-938. https://doi.org/10.1055/s-00341367048

Skorski, S., \& Abbiss, C. R. (2017). The manipulation of pace within endurance sport. Frontiers in Physiology, 8, 102. https://doi.org/10.3389/fphys.2017.00102

Smyth, B. (2018). Fast starters and slow finishers: A large-scale data analysis of pacing at the beginning and end of the marathon for recreational runners. Journal of Sports Analytics, 4(3), 229-242.

Thiel, C., Foster, C., Banzer, W., \& De Koning, J. (2012). Pacing in Olympic track races: Competitive tactics versus best performance strategy. Journal of Sports Sciences, 30(11), 1107-1115. https://doi.org/10.1080/02640414.2012.701759

Tomazini, F., Pasqua, L. A., Damasceno, M. V., Silva-Cavalcante, M. D., de Oliveira, F. R., Lima-Silva, A. E., \& Bertuzzi, R. (2015). Head-to-head running race simulation alters pacing strategy, performance, and mood state. Physiol. Behav., 149, 39-44. https://doi.org/10.1016/ j.physbeh.2015.05.021

Tucker, R., \& Noakes, T. D. (2009). The physiological regulation of pacing strategy during exercise. British Journal of Sports Medicine, 43(e1), 1-9. https://doi.org/10.1136/bjsm.2009. 057562

Van Biesen, D., Hettinga, F. J., McCulloch, K., \& Vanlandewijck, Y. (2016). Pacing profiles in competitive track races: Regulation of exercise intensity is related to cognitive ability. Frontiers in Physiology, 7, 624. https://doi.org/10.3389/fphys.2016.00624

Watkins, J., Platt, S., Andersson, E., \& McGawley, K. (2017). Pacing strategies and metabolic responses during 4-minute running time trials. International Journal of Sports Physiology and Performance, 12(9), 1143-1150. https://doi.org/10.1123/ijspp.2016-0341

Wu, S. S. X., Peiffer, J. J., Brisswalter, J., Nosaka, K., Lau, W. Y., \& Abbiss, C. R. (2015). Pacing strategies during the swim, cycle and run disciplines of sprint, Olympic and half-Ironman triathlons. European Journal of Applied Physiology, 115(5), 1147-1154. https://doi.org/10.1007/s00421-014-3096-2 


\section{Copyright Disclaimer}

Copyright for this article is retained by the author(s), with first publication rights granted to the journal.

This is an open-access article distributed under the terms and conditions of the Creative Commons Attribution license (http://creativecommons.org/licenses/by/3.0/). 